\title{
La Compañía Trasatlántica en el Perú. Intereses diplomáticos y comerciales en la génesis y desarrollo de una empresa arriesgada (1899-1935)
}

Ascensión Martínez Riaza

Universidad Complutense de Madrid

Entre 1923 y 1928 la Compañía Trasatlántica, la gran empresa naviera del marqués de Comillas, estableció una línea regular a los puertos del Pacífico a través del Canal de Panamá, llegando al Perú. Es la historia de un proyecto complejo en el que se movieron intereses políticos y económicos y que nació lastrado por dificultades que llevaron a una supresión anunciada desde muy temprano. Para rastrear sus antecedentes y su evolución se sigue la actuación de los representantes diplomáticos y consulares españoles en Lima, así como la de los comerciantes y empresarios organizados en la Cámara Oficial Española de Comercio del Perú.

Palabras ClaVE: Perú-España, diplomacia, relaciones comerciales, comunicaciones, Compañía Trasatlántica.

Between 1923 and 1928 the Transatlantic Company, the great shipping enterprise belonging to the Marquis of Comillas, established a regular service to the Pacific ports of Peru through the Panama Canal. This business venture was a complex project involving both economic and political interests, which was born amid difficulties that condemned it to failure almost from the start. The origins and evolution of this project are traced in this essay through the actions of the Spanish diplomatic and consular representatives in Lima, and of the merchants and businessmen who were members of the Official Spanish Chamber of Commerce in Peru.

Keywords: Peru-Spain, Diplomacy, Commerce, Communications, Trasatlantic Company.

Entre 1923 y 1928 la Compañía Trasatlántica, el gran gigante naviero del marqués de Comillas, sirvió regularmente a los puertos del Callao y Valparaíso. Es la historia, poco conocida, de un proyecto complejo en el que se movieron intereses políticos y económicos, que nació lastrado por dificultades que se revelaron irresolubles y que llevaron a una desaparición anunciada desde muy temprano. Estuvieron implicados representantes diplomáticos y consulares en Lima, así como sectores vinculados al comercio, especialmente la Cámara Oficial Española de Comercio del Perú (COECP). Este tra-

1 Este trabajo forma parte del Proyecto de Investigación BHA2002-1224-C02-02, Relaciones el Perú y España: política oficial, instituciones y redes sociales (1879-1930), financiado por el Ministerio de Ciencia y Tecnología de España. 
bajo trata de rescatar el proceso que llevó a la Trasatlántica a extender una de sus líneas al Pacífico a través del Canal de Panamá. En su desarrollo se partirá de la situación de origen, es decir de la ausencia de buques de bandera española en aquellos espacios y el predominio de compañías de procedencia británica, italiana, alemana e incluso holandesa en el intercambio entre esos puertos y los españoles. Se expondrán las propuestas pioneras que planteaban alternativas para romper el aislamiento y se desvelarán los términos de la primera incursión de la Trasatlántica en un puerto peruano en 1918. Se incidirá en la insistencia, a partir de entonces, para que se concretara el proyecto, encabezada en el Perú por los ministros plenipotenciarios y el Consulado en Lima, además de por los delegados de la Casa de América de Barcelona y, desde su reorganización, por la Cámara Oficial Española de Comercio del Perú. En España se movilizaron los cónsules del Perú en Barcelona y elementos del comercio catalán vinculados a la mencionada Casa de América. Se seguirá la actividad de la Trasatlántica, condicionada desde el comienzo por problemas de diversa índole. Finalmente se llegará a las razones de la supresión del servicio, en las que convergieron, como en su gestación, condicionantes económicos y de índole política. ${ }^{2}$

\section{Introducción}

El restablecimiento definitivo de las relaciones entre el Perú y España, sellado en el Tratado de Paz y Amistad firmado en París el 14 de agosto de 1879, posibilitó nuevas vías de acercamiento entre ambos países. Desde las instancias oficiales se promovieron iniciativas políticas y culturales con resultados desiguales. ${ }^{3}$ Fueron los gobiernos peruanos los que dieron los

2 Las pistas iniciales, muy escuetas, fueron apareciendo aleatoriamente en la documentación consultada en la investigación general sobre las relaciones en Perú y España. La presencia de la Trasatlántica en el Perú no está registrada en la bibliografía consultada sobre la Compañía. La reconstrucción se ha hecho a partir de fuentes inéditas y editadas, aunque éstas escasamente conocidas. Ha sido fundamental la consulta de los fondos del Ministerio de Asuntos Exteriores de España, del de Relaciones Exteriores del Perú y de la Fundación Figueras de Barcelona. La orientación y profesionalidad de Yolanda Bisso y Nancy Herrera en Lima y Fuensanta Marmolejo en Barcelona han sido definitivas para la elaboración del trabajo.

3 Para una síntesis de la evolución de las relaciones entre el Perú y España, ver Martínez Riaza, Ascensión: "El Perú y España: relaciones político institucionales", en El Perú y España. Un siglo de historia, Pontificia Universidad Católica del Perú- Academia Nacional de la Historia del PerúAgencia Española de Cooperación Internacional, Lima, 2000, págs. 9-28. El diplomático Fabián Novack Talavera ofrece un panorama general desde la perspectiva peruana en: Las relaciones entre el Perú y España (1821-2000), Pontificia Universidad Católica del Perú-Instituto de Estudios Internacionales, Lima, 2001. 
pasos más firmes, acudiendo a la Corona española para que actuara como árbitro en la resolución de conflictos de límites con países vecinos. Era un modo de reconocerle una autoridad moral en entredicho durante décadas. Esta actitud favorable no fue sin embargo aprovechada por la clase política española, que priorizaba otros temas y otros escenarios en el diseño y gestión de las relaciones internacionales encomendadas al Ministerio de Estado. ${ }^{4}$ Una excepción fue la cobertura que Antonio Cánovas del Castillo proporcionó a los actos del IV Centenario de Descubrimiento de América, en los que la presencia peruana fue notable.

Hasta el Oncenio de Leguía (1919-1930) fueron los vínculos científicos y culturales, tanto a nivel individual como institucional, los que sirvieron de plataforma al intercambio, en un panorama general de relaciones diplomáticas sin incidentes relevantes pero poco intensas, en el que hay que ponderar la actuación extraoficial de personas de peso en la vida pública que formaban parte de redes familiares y de amistad con anclaje en ambos países. A la hora de buscar incentivos que reactivaran las relaciones hubo voces que plantearon la necesidad perentoria de salvar uno de los mayores obstáculos: la distancia, agravada por la ausencia de comunicaciones que había cortocircuitado históricamente las posibilidades de acercamiento. De ahí que defendieran, con argumentos más o menos realistas, la llegada al Pacífico sur de una compañía de navegación española que facilitara el intercambio comercial y humano, rompiendo la dependencia de líneas extranjeras.

\section{La Trasatlántica entra en escena}

La Trasatlántica había tenido una predecesora, tan arriesgada como poco exitosa, en los primeros tiempos del restablecimiento de las relaciones bilaterales. Apenas establecida la representación diplomática y consular en el Perú (marzo y abril de 1880 respectivamente), un empresario español, el marqués de Campo, se había atrevido a inaugurar la primera línea al Pacífico enviando a Valparaíso y el Callao, vía Estrecho de Magallanes, al buque "España". Era el mes de noviembre de 1882 y las circunstancias no

4 Martínez Riaza, Ascensión: "Estrategias de ocupación de la Amazonía. La posición española en el conflicto el Perú-Ecuador (1887-1910)", en García Jordán, Pilar (ed.): Fronteras, colonización y mano de obra en la Amazonía andina siglos XIX y XX, , Universitat Barcelona-Pontificia Universidad Católica del Perú, Lima-Barcelona, 1998, págs. 241-335; y "La estela del 98: la diplomacia española y el frustrado arbitraje de la Corona en el conflicto Perú-Chile (1892-1906)", en Homenaje a Félix Denegri, Pontificia Universidad Católica, Lima, 2000, págs. 442-468. 
podían ser más adversas: el Perú y Chile estaban en guerra y Lima se hallaba ocupada por el ejército invasor. Sobrevolando la realidad de una actividad comercial paralizada, el primer cónsul español Ernesto Merlé expresaba sus deseos cuando adelantaba que había carga y pasajeros suficientes para el viaje de retorno. Pero no fue así, el "España" regresó de vacío y el marqués de Campo desistió de repetir tan frustrante experiencia. ${ }^{5}$ El testigo sería recogido veinte años más tarde por el marqués de Comillas, pero hasta entonces el escaso intercambio comercial entre España y el Perú sería deudor de intermediarios.

\section{Un poco de historia}

Antes de 1923, los puertos peruanos del Pacífico estaban servidos por compañías de distinta procedencia. El cabotaje estaba a cargo de dos navieras: la Compañía Peruana de Vapores, fundada en 1907, que transportaba pasajeros y carga entre Colón e Ilo (al sur del Perú), ${ }^{6}$ y la Compañía Sud Americana de Vapores, establecida en Valparaíso en 1870 y que conectaba este puerto con Nueva York, recalando en paradas intermedias. Las comunicaciones con Europa eran mantenidas por las británicas Pacific Steam Navigation Co., que hacía trayecto mensual desde Valparaíso a Nueva York, y la Royal Mail Steam Packet, en servicio de Valparaíso a Liverpool, ambas con escala en el Callao. Estaban además la alemana Kosmos-Roland, que después de la interrupción motivada por la guerra reanudó su servicio tanto por Panamá (hasta Hamburgo) como por el Estrecho de Magallanes, y la italiana La Veloce, que conectaba el Callao con puertos del Mediterráneo. Además ganaba importancia la norteamericana Grace Line, que operaba de Valparaíso a Nueva York vía Canal de Panamá y servía varios puertos peruanos.?

5 Archivo del Ministerio de Asuntos Exteriores de España (AMAE). H. 1931. Correspondencia del Consulado de España en Lima. Ernesto Merlé al ministro de Estado. El Callao, 5 y 12 de noviembre de 1882. Casi un año después, el 23 de junio de 1883, el cónsul conocía a través de la prensa de Lima la decisión del marqués de Campo.

6 El proyecto de creación de una Marina Mercante Nacional de Vapores y Dique del Callao se discutió en las sesiones del legislativo a lo largo de 1905. La ley que serviría de marco se aprobó el 6 de febrero de 1906. A partir de ella un grupo de capitalistas presentó una propuesta para organizar una sociedad anónima, la Compañía Peruana de Vapores y Dique Flotante del Callao, que fue aceptada por el gobierno. Los estatutos fueron aprobados el 9 de febrero de 1907. Basadre, Jorge: Historia de la República del Perú, VIII, Editorial Universitaria, Lima, 1983, págs. 150-151.

7 La información sobre estas líneas de navegación aparece en distintos documentos, por ejemplo en los informes consulares. Este resumen procede del Boletín de la Cámara Oficial Española de Comercio del Perú, (BCOECP), III, 4, Lima, 17 de mayo de 1923, págs. 3-8. 
A la hora de plantearse cómo podían los buques españoles entrar en ese circuito, no es de extrañar que las miradas recayeran en la Compañía Trasatlántica por varias razones. Era la única que contaba con experiencia de servicio a puertos americanos. Se trataba de una firma vinculada a un gran conglomerado de propiedades y negocios, que operaba a partir de una imponente infraestructura administrativa con base en Madrid y sede social en Barcelona. Entre sus recursos estaba la construcción naval en los astilleros de Matagorda (Cádiz). Y además era una empresa subvencionada, es decir financiada en parte con cargo a los presupuestos del Estado.

El indiano cántabro Antonio López y López (1817-1883) había fundado la naviera A. López y Cía en Madrid en 1857. En 1861 consiguió la adjudicación gubernamental del transporte de la correspondencia pública entre la península, Cuba, Puerto Rico y Santo Domingo, a lo que se añadió el traslado de soldados a Santo Domingo (1863-1865) y a Cuba durante la Guerra de los Diez Años (1868-1878). ${ }^{8}$ El volumen de la flota fue creciendo al hilo de la expansión de la Compañía que se cimentó en buena medida en una estrategia relacional y de pactos con los gobiernos conservadores de la Restauración. En 1878 la naviera contaba con 13 vapores para sus líneas regulares desde Santander y Cádiz a Cuba y Puerto Rico. Por su lealtad y patriotismo, Alfonso XII concedería a Antonio López el marquesado de Comillas. En 1881 la empresa se transformaba en una sociedad anónima, la Compañía Trasatlántica. En 1883 Claudio López Bru (1853-1925) heredaba de su padre el título de nobleza y un legado económico que lo convertía en el primer empresario español de su tiempo. En la agenda de la Junta Directiva que presidía se incluyó la negociación de un contrato que se firmó en 1887 y que supuso un notable aumento de ayudas a la Trasatlántica para la subvención de líneas, al tiempo que sentenciaba su dependencia del gobierno. Se prolongaba el servicio que llegaba a Cuba hasta Veracruz, Nueva York y Colón y se creaba uno nuevo a los puertos del Plata (Buenos Aires y Montevideo). Se establecía otro de Vigo a Colón con escalas en Puerto Rico, La Habana, Santiago, La Guaira y otros puertos del Caribe, partiendo los vapores unas veces de Liverpool y el Havre, y otras de Génova y Barcelona. Pero, según información de la propia Compañía, no dio buenos resultados y fue suspendido en $1891 .{ }^{9}$

8 Hernández Sandoica, Elena: "Transporte marítimo y horizonte ultramarino en la España del siglo XIX: la naviera "Antonio López" y el servicio de Correos a las Antillas", Cuadernos de Historia Contemporánea, 10, Madrid, 1988, págs. 45-70.

9 Para elaborar la trayectoria de la Trasatlántica se ha acudido a la completa investigación de Martín Rodrigo Alharilla: Los marqueses de Comillas 1817-1925. Antonio y Claudio López, Lid, Editorial Empresarial, Madrid, 2001. 
En los actos de celebración del IV Centenario del Descubrimiento en 1892 la Trasatlántica ofreció sus servicios, y el vapor "Joaquín Piélago", que había sido botado ese año, participó en la fiesta naval que se celebró en Huelva, distinguiéndose entre las casi cien embarcaciones de diferentes nacionalidades que rindieron honores a Colón, sirviendo como hotel flotante a los invitados extranjeros..$^{10}$ Durante la guerra hispano cubano norteamericana jugaría un papel destacado en el transporte de soldados y tropas, hasta que la declaración de guerra por los Estados Unidos provocó la supresión de casi todas las líneas americanas. ${ }^{11}$ Las informaciones coinciden en señalar el gran negocio que el conflicto supuso para los intereses de la Compañía, que pudo introducir algunos ajustes. Aumentó la importancia de los fletes que se ocupaban del traslado desde las Canarias de grandes contingentes de inmigrantes a Río de Janeiro, Montevideo y Buenos Aires. Y en 1899 añadió un servicio que zarpaba de Liverpool y seguía por La Coruña, Vigo, Oporto, Lisboa, Cádiz, Las Palmas, Río de Janeiro, Montevideo, Buenos Aires, Punta Arenas, Coronel y destino final Valparaíso. ${ }^{12}$ América crecía en importancia en la cartera de negocios de la Trasatlántica, que envió agentes a distintas repúblicas para hacer trabajos de sondeo y propaganda. El Perú no entró en las previsiones de entonces.

La Ley de Comunicaciones de 14 de junio de 1909, apoyada por el presidente del Consejo de Ministros Antonio Maura, incrementó aún más los privilegios de que gozaba la Trasatlántica mediante la remodelación del sistema de primas y subvenciones. La justificación política esgrimida fue que era la manera de contar con una compañía española en condiciones de competir con las extranjeras. ${ }^{13}$ La Primera Guerra Mundial trastornó el funcionamiento de las líneas regulares. En los años siguientes la Compañía se resentiría de la crisis del sistema de la Restauración y de la muerte del

10 Joaquín del Piélago fue cuñado de Claudio López Bru. Aunque su mujer falleció en el mismo año del matrimonio y no hubo hijos, continuó muy cercano al poder y fue gerente de la Trasatlántica desde 1881 hasta su muerte en 1890. Para seguir la formación de redes familiares y empresariales de la burguesía catalana, McDonogh, Gary Wray: Las buenas familias de Barcelona. Historia social de poder en la era industrial, Ediciones Omega, Barcelona, 1989. Las conexiones personales y profesionales de Antonio López se tratan específicamente en las págs. 92-93, 125-133 y 280-289.

11 Llorca Baus, Carlos: La Compañía Trasatlántica en las campañas de Ultramar, Ministerio de Defensa, Madrid, 1990.

12 Rodrigo Alharilla: Los marqueses de Comillas..., pág. 237.

13 En un trabajo previo Rodrigo Alharilla remite al alineamiento político del segundo marqués de Comillas, que se significó apostando por los conservadores por cuanto eran los que mejor garantizaban el orden que defendía, aunque no tuvo militancia partidaria, en Rodrigo Alharilla, Martín: "Hegemonía, consenso y conflicto: una historia social del poder en la Restauración", Historia Social, 35, Madrid, 2000, págs. 35-55. 
segundo marqués de Comillas, Claudio López Bru, en 1925. A ello se sumaron los efectos de la crisis de 1929. Las consecuencias fueron palpables: se suprimieron líneas, se canceló el servicio de correos entre Santa Cruz de Tenerife y puertos americanos, y en 1931 las líneas de Montevideo y Buenos Aires fueron adjudicadas a la naviera Ybarra. Eran ya los tiempos de la Segunda República, cuyos gobernantes no favorecieron a una empresa de significadas connotaciones sociales, económicas y políticas. Por Decreto de 5 de mayo y Ley de 23 de julio de 1932 se rescindía el contrato vigente entre la empresa y el Estado, firmado el 21 de agosto de 1925 y que prorrogaba el de junio de 1910. Quedaron en funcionamiento unas pocas líneas en precario: la que conectaba los puertos del Cantábrico con Cuba, México y Nueva York; la del Mediterráneo a Cuba, Nueva York y Centro América; y la del Mediterráneo a Venezuela y Colombia. ${ }^{14}$

\section{Los primeros rastros}

Los primeros rastros documentados sobre la posibilidad de que la Compañía Trasatlántica llegara al Perú se remontan a 1899 y remiten a la gestión del ministro plenipotenciario español en Lima Ramiro Gil de Uribarri. ${ }^{15}$ En enero de ese año enviaba un Memorandum al Ministerio de Estado argumentando la conveniencia del establecimiento de una línea de navegación española hasta el Callao que contribuyera a desarrollar las relaciones comerciales y a potenciar el intercambio humano que "reavivaría el sentimiento español", al abrir la posibilidad de que americanos "visitaran en la vieja España la tumba de sus mayores" y advirtieran el cariño que se les tiene. La Trasatlántica sería la encargada, porque "tiene materiales cuantiosos para hacerlo y además tiene interés". El itinerario sería prolongación del que llegaba al Brasil y las Repúblicas del Plata, desde ahí debería extenderse para cruzar el Estrecho de Magallanes y recalar en Valparaíso, el Callao, Guayaquil e incluso Panamá. El gobierno peruano

14 En esta breve referencia se han incluido sobre todo datos relacionados con Hispanoamérica. Como es sabido la Trasatlántica sirvió también a Filipinas y puertos africanos. Para más información sobre la historia de la Trasatlántica consultar además a Francisco de Cossío, que hace la "historia oficial" de la Compañía: La Compañía Trasatlántica. Cien años de vida sobre el mar, Compañía Trasatlántica, Madrid, 1950; y Martínez Romero, Francisca: "Don Antonio López, marqués de Comillas: su vinculación con Cádiz y América”, Cádiz e Iberoamérica, 6, Cádiz, 1988, págs. 18-22.

15 Gil de Uribarri fue nombrado ministro plenipotenciario de segunda clase en el Perú por real decreto de 28 de julio de 1898 y permanecería al frente de la legación hasta su traslado a Buenos Aires por otro decreto real de 22 de diciembre de 1904. 
debería colaborar, "bien concertando el tráfico de cabotaje, ya con rebajas o exención de derechos, y confiándole servicios remunerados como el de correspondencia y emigrantes..." 16

No tardaría en informar al ministro de Estado, Francisco Silvela, de los resultados de una entrevista con el nuevo presidente constitucional Eduardo López de Romaña (1899-1903), muy favorable a la intensificación de las relaciones y a la llegada de inmigrantes y buques españoles. Le ponía en antecedentes de los contactos que ya había establecido con su predecesor Nicolás de Piérola (1895-1899) y con el representante de la Compañía, señor Eyzaguirre. Los tres habían coincidido en que, a pesar de las buenas intenciones, no se daban las condiciones de rentabilidad que la empresa requería. López de Romaña se mostró receptivo, llegando a ofrecer ayuda económica una vez que el país hubiera recuperado la estabilidad interna. ${ }^{17}$ El representante español le hacía notar las ventajas del acuerdo, advirtiéndole que estaba a punto de firmarse un contrato entre la Trasatlántica y el gobierno chileno, lo que supondría que, en efecto, los buques llegarían a Valparaíso por el Estrecho de Magallanes, quedando sólo una distancia corta hasta alcanzar puertos peruanos. Sin embargo, en su comentario al ministro Silvela, Gil de Uribarri se mostraba cauto y confesaba que, a pesar de la buena disposición del ejecutivo, no creía que el Erario peruano estuviera en condiciones de subvencionar la línea. ${ }^{18}$ En efecto, en 1900 confirmaría la inviabilidad del proyecto.

Durante los años siguientes Colón, en Panamá, continuaría siendo el último puerto al que arribarían los vapores de la Trasatlántica, y desde allí otras compañías trasladarían mercancías y pasajeros al Callao. Las gestiones que desembocarían en la materialización del proyecto fueron largas y esquivas y partieron de distintas instancias. Entre los agentes más activos estuvieron los cónsules del Perú en Barcelona, centro neurálgico de los movimientos comerciales. Una de sus funciones era dar cuenta del estado del intercambio especificando productos, volumen y valor de los mismos.

16 AMAE. Política Exterior, 2601. Legación de España en Lima. Lima, 24 de enero de 1899 El asunto adquiere la suficiente envergadura como para ser recogido por el canciller del Perú Melitón Porras, en Memoria del Ministerio de Relaciones Exteriores, 1899. Lima, El Tiempo, 1899, págs. 387-391.

17 Así sucedería, abriéndose un largo periodo de control civilista del aparato de Estado, sólo cuestionado seriamente por el gobierno de Guillermo Billinghurst en 1912 y el golpe militar de Oscar Benavides en 1914. Los entresijos del poder han sido desentrañados por Carmen Mc Evoy en La Utopía Republicana, Pontificia Universidad Católica, Lima, 1997, págs. 313-433.

18 AMAE. Política Exterior, 2601, 95. Legación de España en Lima. El ministro plenipotenciario Ramiro Gil de Uribarri al ministro de Estado. Lima, 15 de septiembre de 1899. 
En la interpretación de los datos hacían repetidas alusiones a la responsabilidad que en los bajos índices del comercio tenía la falta de comunicaciones directas. Pedro Company, al frente del Consulado entre 1908 y 1912, fue uno de los más prolijos en sus informes, en los que introducía sistemáticamente a las compañías de navegación. En uno de ellos especificaba cómo en el segundo semestre de 1912 se habían encargado de las exportaciones desde el puerto barcelonés 25 barcos de vapor, de ellos seis pertenecientes a la Trasatlántica con transbordo en Colón. ${ }^{19}$

A pesar de los avatares, la representación diplomática española siguió apostando por la causa. En 1917 Julio Galarza ${ }^{20}$ elevaba al subsecretario de Estado una petición para que la Trasatlántica designara a un agente en Lima y el Callao con el fin de que se ocupara de preparar el terreno de cara a unas negociaciones formales. Recomendaba para el cargo a Bernardo Fernández, entonces vicecónsul español. El Ministerio hizo el trámite, pero la Compañía no creyó necesario el nombramiento, ya que no tenía tráfico directo con el Pacífico. ${ }^{21}$

\section{La experiencia fallida del "Isla de Panay"}

La guerra mundial distorsionaría los circuitos interoceánicos, sobre todo una vez que los Estados Unidos entraron en combate. De nuevo hay que acudir a los agentes consulares en Barcelona para conseguir pistas que permitan seguir el proceso. Según Rogelio Bascones, las exportaciones durante el año 1917 se habían efectuado en 15 vapores, de ellos 12 de la Trasatlántica con transbordo en Colón y sólo uno de La Veloce, es decir, la Compañía salía ampliamente beneficiada de la neutralidad española..$^{22}$ José Gálvez, titular desde comienzos de 1918 hasta finales de 1919, sería un promotor fundamental de las iniciativas, tanto por su buena relación con los

19 Boletín del Ministerio de Relaciones Exteriores del Perú (BMRREE), año 10, XLIX, La Industria, Lima, 1913, pág. 87.

20 Julio Galarza fue encargado de negocios en Lima desde el 3 de julio de 1916 y ministro residente desde el 21 de septiembre de 1917 al 23 de octubre de 1919.

21 Archivo General de la Administración de España (AGA). Asuntos Exteriores, caja 1758. Julio Galarza al marqués de Amposta, Lima, 25 de julio de 1917. La respuesta negativa de la Trasatlántica tiene fecha de 2 de octubre de 1917.

22 Bascones se ocupó interinamente del consulado del Perú en Barcelona hasta la incorporación del titular José Gálvez. En ese tiempo elaboró un extenso informe fechado en Barcelona el 1 de enero de 1918. BMRREE, XVIII, LXV, Imprenta Americana, Lima, 1922, pág. 172 (adviértase que el Boletín sale con un considerable retraso). 
principales intereses en juego como por la seriedad y profesionalidad de su gestión. ${ }^{23}$ En sus frecuentes misivas al Ministerio de Relaciones Exteriores, informaba y también aconsejaba, y en ellas aparecía como una constante la preocupación por el estado de las comunicaciones en momentos difíciles para el comercio trasatlántico. Con la intervención de los Estados Unidos, recapitulaba Gálvez, los alemanes comenzaron a crear dificultades a la Trasatlántica porque La Habana, Puerto Rico y Colón eran consideradas plazas de guerra norteamericanas. La Compañía hubo de someterse a las directrices de no transportar mercaderías calificadas como contrabando, y en ocasiones se vio obligada a suspender expediciones de sus líneas Nueva York-Cuba-México, y Venezuela-Colombia. Ésta segunda interesaba particularmente al Perú porque hacía el servicio de las Antillas, países centroamericanos, Venezuela, Colombia y Panamá (punto de transbordo a otras compañías que seguían a Ecuador, Perú y Chile). El cónsul ofrecía una alternativa, que la Trasatlántica estableciera una línea al Pacífico que partiendo desde España (no especificaba puerto, pero pensaba obviamente en Barcelona), continuara a Punta Arenas, Talcahuano, Valparaíso, Antofagasta, Iquique, Mollendo y Callao. Este servicio sería sumamente beneficioso porque, además de la carga que habitualmente llevaba, podría transportar de retorno algodón peruano, cueros de res, lanas y otros muchos productos que Europa demandaba. ${ }^{24}$

No pasaría mucho tiempo antes de que su propuesta se materializara y Gálvez estuviera en condiciones de comunicar que la Trasatlántica había designado al vapor "Isla de Panay" para cubrir esa ruta. Más tarde explicaría cómo jugaron las presiones de los comerciantes de Barcelona que, debido a las restricciones, encontraron sus depósitos saturados de mercancías a las que querían dar salida. Con la intermediación de la Casa de América se dirigieron al gobierno español que dio instrucciones a la Trasatlántica para que designara a un buque especial con destino a los puertos del Pacífico. ${ }^{25}$

23 José Gálvez Barrenechea (1885-1957) perteneció a la élite social peruana y mantuvo una intensa relación con España. Su nombramiento como cónsul por el presidente José Pardo se debió precisamente a sus conexiones con españoles en el Perú y la propia España.

24 Consulado del Perú en Barcelona. José Gálvez al oficial mayor del Ministerio de Relaciones Exteriores, Barcelona, 17 de mayo de 1918. En BMRREE, XVIII, LXVI, Imprenta Americana, Lima, 1922, págs. 180-183.

25 Memoria Consular, Barcelona, 24 de mayo de 1919. Ibidem, págs. 213-214. La Casa de América nació el 2 de abril de 1911, a impulso de grupos catalanes e hispanoamericanos, para promover las relaciones, especialmente las comerciales, entre España e Iberoamérica. Entre sus iniciativas estuvo la organización de dos Congresos Nacionales del Comercio Español en Ultramar y la promoción en 1923 de una Junta Nacional del Comercio Español en Ultramar. En 1927 cambió su denominación 
El cargamento se componía exclusivamente de productos catalanes $(2.250$ bultos por valor de 960.151 ptas.). ${ }^{26}$

La noticia fue acogida con expectación. El delegado de la Casa de América en Lima desde 1918, Luis Fábrega, interpretó el sentir de los comerciantes y empresarios españoles ${ }^{27}$ que, sin respaldo del gobierno, venían ejerciendo "un verdadero apostolado en el intercambio comercial y de ideas". Mandando un vapor "al continente del Sur de América" España había hecho más que todos los discursos y libros y había demostrado su interés por romper el predominio las compañías extranjeras en los puertos del Pacífico. Yendo a lo práctico - Fábrega era además representante de firmas, y por tanto parte interesada - podía suponer el principio de un intercambio rápido y fluido que cubriera los pedidos pendientes que esperaban turno en los puertos y que no podían salir por falta de fletes. ${ }^{28}$ En los siguientes días se convertiría en cronista de lo que fue una operación desastrosa. El "Isla de Panay" arribó al Callao el domingo 15 de septiembre de 1918 y partió sólo tres días más tarde. Por primera vez en mucho tiempo el pabellón español ondeaba en el puerto peruano y muchos miembros de la colonia acudieron a visitarlo. El espectáculo social se solapó con consideraciones de carácter pragmático relativas a cual sería la carga que el buque transportaría en el retorno y en qué condiciones. Y cundió el desánimo cuando quedó en evidencia la falta de previsión y la política errada de la Trasatlántica. En lugar de aprovechar la ocasión y recoger productos (especialmente azúcar) en distintos puertos menores a tasas razonables, el capitán Gimbernau cumplió las órdenes de no hacer cabotaje y cobrar unas tasas absolutamente prohibitivas a los que cargaría en el Callao, que por lo menos duplicaban a las de compañías extranjeras. De nada sirvió el ofrecimiento de algunos comerciantes de entregar azúcar pagando precios más elevados de los que pedía la

por la de Instituto de Economía Americana. Actualmente sus fondos documentales se encuentran en la Fundación Figueras de Barcelona. Para seguir su evolución, Yáñez Gallardo, César: El americanismo de la burguesía catalana 1898-1929. Un proyecto imperialista, Universidad Autónoma, Barcelona, 1985 (Tesis de Licenciatura inédita).

26 Así lo especificaba un artículo elaborado con información de Gálvez que apareció en el Mercurio. Revista Comercial Ibero Americana, XVIII, 315, Barcelona, 12 de septiembre de 1918, págs. 226-227.

27 En esos momentos la Cámara Oficial Española de Comercio del Perú era una institución aletargada, sin peso específico ni poder de convocatoria. Más activa se mostraba la delegación de la Casa de América que trataba de armar una infraestructura propia en el Perú. A pesar de compartir objetivos, fueron dos asociaciones paralelas. Por ejemplo Fábrega nunca sería socio de la Cámara Española de Comercio.

28 Fundación Figueras. Casa de América de Barcelona. Información. Perú. Dirección General de la Casa de América. Luis Fábrega, representante, Lima, 29 de julio de 1918. 
competencia, ni siquiera Fábrega consiguió enviar una cantidad de caucho. En contra de todos los criterios de racionalidad, el "Isla de Panay" regresó casi de vacío. A pesar de todo su juicio no fue muy severo, y más bien se permitió, a través de la Casa de América, aconsejar a la Trasatlántica que estableciera una oficina en Lima que informara y ayudara a planificar futuros viajes, y estableciera tarifas de fletes competitivas. ${ }^{29}$

Para la prensa peruana no fue noticia de primera plana. Dos de los diarios más importantes de Lima, La Prensa y La Crónica, coincidieron en valorar positivamente el gesto del gobierno español (dado que se trataba de una compañía subvencionada), aunque dieron al acontecimiento un enfoque diferente. El comentario de La Prensa corrió a cargo de Antonio Garland, un reconocido amigo de España, que en el título de su artículo, "Hispania Mater", anunciaba contenidos de "acendrado españolismo". Envolvía la defensa de los valores compartidos del idioma, religión y costumbres en un discurso modernizador que miraba al futuro, al añadirse el factor dinámico del intercambio comercial. Sólo lamentaba que un suceso de tamaña envergadura hubiera pasado inadvertido por la escasa propaganda que le habían dado, tanto la propia Compañía como los hombres de negocios peruanos. ${ }^{30}$ La nota de La Crónica — sin título ni firma - era más dura y reveladora. El "Isla de Panay" regresaba a España en lastre, cargando apenas cuarenta o cincuenta toneladas de pieles y quebrando las esperanzas de que pudiera ser el inicio de una corriente franca de comercio entre las dos naciones. A la hora de buscar explicaciones remitía, por un lado, a "la falta de espíritu práctico y comercial que caracteriza a los industriales españoles y en especial a los catalanes, y a la hostilidad que el agente general de la Compañía Trasatlántica Barcelonesa ha manifestado contra nuestros productos, señalándoles, maliciosamente, un flete casi groseramente prohibitivo". A estos argumentos añadía otro que tocaba especialmente la sensibilidad de los peruanos: la preeminencia que la Trasatlántica daba a Chile, ya que Valparaíso contaba con agentes que fijaban los fletes a pagar por el algodón peruano en tasas muy superiores a los que cobraban otras compañías, “...Se comprende que por grande que fuera el anhelo de nuestros productores de

29 Ibidem. Informe referente a la llegada del vapor "Isla de Panay" al puerto del Callao, dado a la Casa de América de Barcelona por su delegado general en Lima, Lima 19, de septiembre de 1918.

30 La Prensa, Lima, 18 de septiembre de 1918. El periódico había sido fundado el 23 de septiembre de 1903 por Pedro de Osma y Pardo para impulsar el proyecto del Partido Demócrata. A partir de 1915 cambió de propiedad y apoyó a los civilistas. Gargurevich, Juan: Historia de la prensa peruana 1594-1990, La Voz, Lima, 1991, págs. 115-120. Antonio Garland estuvo vinculado a intereses catalanes y de hecho ocupó el Consulado del Perú en Barcelona a comienzos de 1920. 
algodón de enviar su producto a España, no llevarían su abnegación hasta el extremo de pagar casi el triple de flete. Y lo que sucedía con el algodón se repetía con los demás artículos de producción nacional". ${ }^{31}$

Ni Fábrega ni Gálvez tirarían la toalla. Lo sucedido con el "Isla de Panay" debía servir de experiencia. El gobierno español tendría que implicarse estableciendo un sistema de bonificaciones y subvenciones que alentaran a una compañía nacional, porque "...es una vergüenza para nosotros que los que han dado ni su sangre, ni nada a este continente, sean los que desempeñen el rol que debería desempeñar España...". ${ }^{32}$ Gálvez, en la Memoria consular correspondiente a las actividades de 1918, dedicaba un apartado a las vías comerciales con alusión especial a la Trasatlántica, que seguía siendo la principal compañía que llevaba los productos catalanes al Perú, aunque sólo hasta Colón, e insistía en la prolongación al Pacífico “...con lo que ganaría muchísimo el comercio catalán y aprovecharían de la ventaja tanto nuestros importadores como los exportadores, que en realidad casi no hacen hoy con España transacciones por falta de elementos de transporte...". ${ }^{33}$

\section{Nuevas condiciones, nuevas demandas. La Trasatlántica en el Perú}

A partir de 1919 las relaciones diplomáticas y culturales entre el Perú y España se intensificaron notablemente. El acercamiento se hizo más patente durante la dictadura de Primo de Rivera, que cuidó la dimensión hispanoamericana de su política exterior (la culminación fueron las exposiciones de Barcelona y Sevilla en 1929). ${ }^{34}$ Los representantes diplomáticos designados

31 La Crónica, Lima, 21 de septiembre de 1918. La Crónica apareció el 7 de abril de 1912 bajo la dirección de Clemente Palma y su primer redactor jefe fue José Gálvez Barrenechea, ambos en algún momento cónsules del Perú en Barcelona. Hasta 1919, en que apostó por Leguía, se mantuvo al margen del compromiso político priorizando la crónica social y cultural, Gargurevich: Historia de la prensa..., pág. 121.

32 Fundación Figueras. Casa de América. Perú. Luis Fábrega a Rafael Vehils, director de la Casa de América. Lima, 18 de noviembre de 1919. Acompaña recortes de periódicos con noticias de la presencia en el Callao de buques de La Veloce.

33 BMRREE, 1922, pág. 218.

34 Martínez de Velasco, Ángel: "Relaciones hispanoperuanas durante la Dictadura de Primo de Rivera: el Centenario de Ayacucho", Quinto Centenario, 2, Madrid, Universidad Complutense, 1981, págs. 175-194; Martínez Riaza, Ascensión: "Las buenas relaciones de dos regímenes autoritarios. El Perú y España durante el Oncenio (1919-1930)”, en García Jordán, Pilar, Miquel Izard, y Javier Laviña (coords.): Memoria, Creación e Historia: luchar contra el olvido, Universidad de Barcelona, Barcelona, 1994, págs. 273-291. 
fueron especialmente seleccionados. El presidente Leguía convirtió la legación de Madrid en un espacio familiar destacando a su hermano Eduardo como enviado extraordinario y ministro plenipotenciario desde 1924 a 1930, y colocando a otros parientes en posiciones destacadas. Al frente de la legación de España en Lima estuvo desde 1919 a 1930 Jaime de Ojeda Brooke, hijo de Emilio de Ojeda, representante español en dos ocasiones (1884-1888 y 1890-1894) y muy bien relacionado con la oligarquía peruana. Para entonces la colonia española contaba con una elite granada de comerciantes y empresarios que en 1920 estuvo en condiciones de relanzar la Cámara Oficial Española de Comercio del Perú, a través de la que desplegaría en los años siguientes una intensa actividad. Tanto la representación diplomática como la Cámara de Comercio contaron con un agente especialmente eficaz, el cónsul en Lima entre 1918 y 1938, Antonio Pinilla Rambaud. Del lado español fueron las tres piezas clave que, desde el Perú, defendieron y promovieron una causa tan ambiciosa como inviable.

\section{La cristalización del proyecto}

Sin duda un gran valedor del proyecto, que jugaría sus cartas hasta llegar a utilizar sus conexiones personales con personas vinculadas a la propiedad de la Compañía, fue Jaime de Ojeda y Brooke. El primer movimiento oficial lo realizaba en noviembre de 1919 y lo sustentaba en motivaciones ideológicas y también de carácter práctico. Había asistido a un almuerzo a bordo del vapor "Bologne" para celebrar la inauguración por la compañía italiana Veloce de una línea regular de vapores entre Génova y Valparaíso atravesando el canal de Panamá, y creía su deber señalar al gobierno de S.M. "la necesidad urgente, la imprescindible necesidad de que alguna compañía naviera española tenga el patriotismo de salir de antiguos moldes y de abandonar prejuicios y erróneas creencias, y siga el ejemplo que le dan Italia y otros países...” Añadía su experiencia personal de un viaje largo atravesando el sur del continente. En el trayecto encontró a muchos españoles, y de ellos,

“...no he escuchado más que un solo grito: el que se estableciese una línea regular de vapores españoles al Pacífico. Lo piden el patriotismo y los intereses de muchísimos millares de españoles que por un lado se sienten profundamente humillados al ver que el pabellón de su patria no ondeará jamás sobre estos mares, y por otro, ven lesionados sus intereses desde el momento en que las mercancías que reciben de España mis- 
ma pasan por las garras de multitud de compañías, agencias y administraciones extranjeras antes de llegar a sus manos mermadas, deterioradas, robadas en la mayoría de los casos...". ${ }^{35}$

Entonces no mencionaba específicamente a la Trasatlántica. Sí lo haría en un segundo envite que preparó en unas circunstancias particulares, mientras se encontraba en La Paz en julio de 1922 presentando credenciales como representante español. Su estrategia iba de lo particular a lo general: la conexión directa era fundamental porque así “...la creciente cantidad de mercancías que sale de la metrópoli a Sudamérica vendría en inmejorables condiciones de rapidez, economía y seguridad", además el Pacífico iba a ser en breve "escenario de una encarnizada lucha mercantil" y España debía ser competitiva. ${ }^{36}$

Finalmente en diciembre los tres años de espera parecían haber llegado a su fin. Complacido, comunicaba al ministro de Estado que había recibido la visita del señor Garcés, agente de la Trasatlántica en Colón, que llevaba instrucciones de elaborar un informe prospectivo sobre las posibilidades de prolongar la línea al Pacífico. Garcés incluso había contactado con los que serían sus agentes, los hermanos Gallo, ricos mineros españoles con negocios en Cerro de Pasco y que eran además socios activos de la Cámara Oficial Española de Comercio del Perú. ${ }^{37}$

Los comerciantes y empresarios españoles organizados en la Cámara eran en efecto los principales interesados en el éxito de la operación cuya gestación siguieron puntualmente. En la Memoria correspondiente a 19211922, el presidente Luis Albízuri comunicaba a la Junta General que el representante de la empresa naviera, el citado Garcés, les había solicitado información sobre el movimiento comercial entre la República y España con el propósito de elaborar un estudio a partir del cual la Compañía con-

35 AGA. Asuntos Exteriores, caja 1758. Consulado de España en Lima-Callao, 75, Lima, 25 de noviembre de 1919. Jaime de Ojeda al ministro de Estado. El marqués de Lema se comunicó confidencialmente con Javier Gil y Becerril, apoderado de la Trasatlántica, y le remitió el informe de Ojeda pidiéndole que lo atendiera por razones patrióticas. El 26 de enero de 1920 Gil y Becerril comunicaba al ministro que lo había elevado a sus superiores.

36 Ibídem, La Paz, 2 de julio de 1922. Jaime de Ojeda al ministro de Estado. Entonces los representantes españoles lo eran al tiempo en Ecuador, Perú y Bolivia, con las dificultades de carácter diplomático y operativo (distancias) que ello suscitaba.

37 Ibídem, Lima, diciembre de 1922. Jaime de Ojeda al ministro de Estado. Sólo cierta información empañaba su satisfacción. Parece que la Compañía destacaría a un buque antiguo, el "León XIII", que no podría competir con los de la Steam Navegation Company que hacían el trayecto a España en 22 días. Incluso recomendaba el retraso de la operación hasta que pudieran emplearse vapores modernos. 
sideraría la posibilidad de enviar un vapor una vez al mes a las costas peruanas. $^{38}$

El proyecto cristalizaría cuando una Real Orden de 29 de marzo de 1923 autorizaba a la Trasatlántica a prolongar las doce expediciones anuales de la línea Venezuela-Colombia desde el puerto panameño de Colón a Valparaíso, vía Canal de Panamá, con escalas en puertos peruanos. La resolución tenía lugar en una coyuntura poco favorable para la Compañía, que al iniciarse la década de 1920 era un "gigante con pies de barro". ¿QQué elementos se conjugaron en la toma de tal decisión? ¿Cabría interpretarla como una huida hacia delante de la Trasatlántica y un medio para conseguir nuevos privilegios del gobierno, a cambio como otras veces de su actuación patriótica, dado que los mercados peruanos no ofrecían garantías de obtención de ganancias? ¿La información recabada por los agentes de la Compañía permitía augurar la rentabilidad económica de la operación? ¿Pesaron consideraciones de índole política en un sistema, el de la Restauración, que daba sus últimos estertores, y que tras los fracasos en los escenarios africanos, buscaba nuevos espacios de prestigio? ¿Hasta qué punto se movieron las redes que vinculaban a la Corte de Alfonso XIII con los círculos cercanos a Claudio López Bru?

La decisión final tuvo que ver con el acuerdo tomado en el Primer Congreso Nacional del Comercio Español en Ultramar celebrado en Barcelona, Madrid y Sevilla desde el 21 de marzo al 16 de abril de 1923 y en el que estuvieron presentes tres delegados de la Cámara Oficial Española del Comercio del Perú, Aurelio Díaz Ufano, José Antonio de Menchaca y Cayetano Rosich (comisionado comercial del Ministerio de Estado en las Repúblicas del Pacífico).$^{40}$ La inauguración del servicio se fijó para el mes

38 BCOECP, 2-3, Lima, enero de 1923, pág. 16.

39 La crisis general de los negocios de navegación en los primeros años de la postguerra se tradujeron en un descenso de los fletes y del transporte de pasajeros. En las postrimerías de la Restauración, la Junta de Gobierno de la Trasatlántica logró la aprobación de un Real Decreto de 14 de febrero de 1922 que aumentaba las subvenciones establecidas en la Ley de Comunicación de 1909. Además la propiedad permitió la entrada en el equipo directivo de personalidades del mundo financiero que daban un respiro al balance de resultados, pero quebrara la estructura tradicional de la corporación, Rodrigo Alharilla: Los marqueses de Comillas, págs. 324-325.

40 Primer Congreso Nacional del Comercio Español en Ultramar. Conclusiones, Gráficas Reunidas, Madrid, 1923, pág. 111. Díaz Ufano y Menchaca eran dos pesos pesados de la elite económica española en el Perú. El primero era en 1923 gerente y accionista de la empresa Grandes Molinos del Perú, Peral S.A. una de las principales fábricas de harinas del país. Fue socio de la Cámara de Comercio desde su relanzamiento en 1920 y ocupó varios cargos directivos, entre ellos la Presidencia de 1924 a 1927. Menchaca pertenecía a una familia de origen bilbaino vinculada al negocio del salitre y después al de ferretería. 
de abril y para cubrirlo se destinó al "Manuel Arnús" (nombre del cuñado de López Bru y durante tiempo vicepresidente de la Compañía), construido en Cádiz, de 1.200 toneladas de desplazamiento, turbinas de doble hélice, lujosas cámaras y confort moderno. ${ }^{41}$ En España la Compañía tenía que rendir cuentas al Estado, con el que había establecido contrato y, como era preceptivo, desde 1923 incluiría en los itinerarios que había de entregar a los ministerios competentes (es decir, el de Estado, el de Fomento y el de Marina y Navegación) el correspondiente a la línea 4: la del Mediterráneo a Puerto Rico, Cuba, Venezuela, Colombia y Pacífico. ${ }^{42}$

El gobierno del Perú tomó cartas en el asunto. Al acusar recibo de la notificación, el ministro de Relaciones Exteriores mostraba satisfacción, ya que,

“...Por medio de los buques de la Compañía Trasatlántica ha quedado inaugurado un servicio especial y directo de comunicación marítima entre España y el Perú. El arribo de los barcos al Callao ha dado lugar a que se exteriorice, una vez más el profundo cariño que aquí se guarda a la madre Patria. Esta nueva línea de vapores hará más eficaz y más intenso el intercambio comercial entre los dos países". ${ }^{43}$

Al tiempo recordaba que la Compañía habría de someterse a las resoluciones establecidas en 1924 por el Ministerio de Hacienda y Comercio del Perú y rubricadas por el presidente Leguía. Por un lado gozaría de las mismas franquicias de las que disfrutaban otras compañías (más específicamente la Pacific Steam Navigation, Kosmos, Ronald Line, Trasatlántica Italiana y Real Holandesa) respecto al precio y despacho de sus naves y otros aspectos menores (fumigación, derechos de faro y timbres); por otro quedaba obligada a cumplir con el itinerario mensual ofrecido, conducir

41 Durante la celebración del Primer Congreso del Comercio Español en Ultramar los participantes visitaron los astilleros de Matagorda y conocieron el "Manuel Arnús", ya preparado para inaugurar la línea que uniría a España con Panamá, Ecuador, Perú y Chile. Vida Marítima, órgano de la Liga Marítima Española, XII, 737, Madrid, 30 de abril de 1923, págs. 122-124. El 20 de abril la Compañía mandaba una nota a sus agentes comunicando que el "Manuel Arnús" no estaría a punto, pero que para no aplazar su compromiso enviaría provisionalmente al "León XIII".

42 AGA. Asuntos Exteriores, caja 1754. Líneas de Navegación. Están los folletos y otras anotaciones de distintos servicios de la Trasatlántica. La línea 4 tenía periodicidad mensual. Según el itinerario previsto partía de Barcelona (el 10 de cada mes) y después Valencia (facultativo), Cádiz, Las Palmas, Santa Cruz de Tenerife, Santa Cruz de la Palma (facultativo), Puerto Rico, La Habana, Santiago de Cuba (facultativo), La Guayra, Puerto Cabello (facultativo), Curaçao (facultativo), Colón, Guayaquil, Callao, Mollendo, Arica (facultativo), Iquique (facultativo), Antofagasta (facultativo), y Valparaíso. Según la información proporcionada por la Compañía, la línea estuvo servida por los buques "P. Satrústegui", "Manuel Calvo", "Manuel Arnús", "Reina María Cristina" y "Montevideo".

43 Memoria del Ministro de Relaciones Exteriores 1923. Alberto Salomón, Imprenta La Opinión Nacional, Lima, 1923, pág. 66. 
gratuitamente la correspondencia oficial de la República, y hacer rebaja de un $25 \%$ en los pasajes de empleados públicos y en los fletes de carga del Estado. ${ }^{44}$

\section{Expectativas y prevenciones}

Los representantes en Lima y la Cámara Oficial Española de Comercio se convertirán en los principales referentes para seguir las luces y las sombras de la trayectoria de la Trasatlántica en el Perú. Apenas iniciadas las operaciones, Ojeda se creyó en el deber de aportar una serie de sugerencias para mejorar el servicio. La primera, que la conexión con el Callao se desligara por completo del itinerario de las Antillas, Panamá, Colombia y Venezuela, “...lleno de escalas que para nada interesan a los comerciantes del Pacífico", y que "convierten el viaje del Callao a España en una insoportable peregrinación de 30 a 40 días", mientras que los buques ingleses hacen el mismo trayecto entre 19 y 22 días porque sólo tocan Panamá y La Habana. La segunda, que siguiera el ejemplo de la Steam Navigation, que había reducido las tarifas. El tiempo acabaría dándole la razón y a sus propuestas se sumarían otras voces autorizadas. En su papel de defensor de los intereses españoles en el Perú se atrevió a entrar en una cuestión candente, al propugnar que la ruta terminara en el Callao y no en los puertos chilenos y que los pasajeros que desearan viajar a España lo hicieran desde Buenos Aires. ${ }^{45}$ Se supone que de esta manera quedaba fuera del itinerario el puerto de Valparaíso, centro neurálgico del comercio del Pacífico y sede de una activa colonia española. ${ }^{46}$ Esta preocupación genérica, y seguramente bienintencionada, no obstaría para que, llegado el momento, Ojeda acudiera a sus relaciones para obtener beneficios personales. ¿Quién mejor que su amigo Pablo Churruca, destacado en la Secretaría Particular de Alfonso XIII y cuñado del tercer marqués de Comillas Juan Antonio Güell López? En julio de 1925, en una carta privada, le pedía que

44 Memoria que el Ministro de Hacienda y Comercio, Sr. Marcial Pastor presenta al Congreso Ordinario 1924, La Imprenta Americana, Lima, 1925, págs. 1015-1075.

45 Hay que tener en cuenta que eran momentos difíciles en las relaciones entre el Perú y Chile porque se estaba dirimiendo el futuro de dos territorios en litigio, Tacna y Arica. AGA. Asuntos Exteriores. Caja 1758. Consulado de España en Lima-Callao, 87. Lima, 20 de agosto de 1923. Jaime de Ojeda al ministro de Estado.

46 Estrada Turra, Baldomero: Redes socioeconómicas de los emigrantes españoles en Valparaíso (Chile) a comienzos del siglo XX. Ponencia presentada al X Congreso Internacional de Historia de América de la Asociación Española de Americanistas, Sevilla, julio del 2002. 
terciara para que la Trasatlántica transportara sin costes todos los enseres que necesitaba para amueblar la sede de la legación. Así sucedería cuando el presidente de la Compañía daba orden para el flete gratuito en nota interna fechada el 1 de febrero de $1926 .{ }^{47}$

Durante seis años, de mayo 1923 al mismo mes de 1929, el Boletín de la COECP insertó un anuncio a toda página: "Compañía Trasatlántica de Barcelona. Vapores Correos Españoles. Servicio Regular Mensual entre los puertos de España y los del Sur-Pacífico. Itinerario Fijo. Grandes comodidades a pasajeros de primera, segunda y tercera clase. Agentes: Gallo Hermanos. Lima, Valladolid 246-Callao A King 23". Como parte de la campaña de difusión, en el número correspondiente a mayo de 1923 publicaba una síntesis, sin duda proporcionada por la propia Cámara, de su historia "oficial", que proyectaba una imagen de prosperidad y éxito. ${ }^{48}$

El 12 de octubre, Día de la Raza, y en el marco de las celebraciones programadas, la Cámara daba a conocer un comunicado institucional sobre el alcance del acuerdo. Por fin España había tomado una decisión práctica y eficaz para el acercamiento a las repúblicas del Pacífico, que había supuesto "...una labor más honda y provechosa que todos los diplomáticos y cónsules y enviados especiales españoles durante un siglo de vida independiente...." El arribo del "Manuel Arnús" en el mes de mayo había constituido todo un acontecimiento social y los millares de personas que lo habían visitado habían llegado a bautizarlo como "palacio flotante" ${ }^{49}$ Un gran cronista del momento, Enrique Centurión Herrera, mencionaba el hecho como un logro de "los anhelos de los hombres que en España se preocupan de mirar al futuro de la raza, al mismo tiempo que las conveniencias del negocio". Con el establecimiento de un servicio mensual a los puertos de Venezuela, Colombia, Ecuador, Perú y Chile se ha tendido "un lazo de armonía entre España y las repúblicas que dimanaron de su acción fecunda. Lleva grandes ganancias espirituales a la nación española, y se beneficia con el valor de los pasajes y fletamientos". ${ }^{50}$

47 Archivo General de Palacio (AGP). Madrid. Correspondencia de la Legación de España en Lima con la Secretaría Particular 1921-1929. Los documentos están firmados por Jaime de Ojeda en Lima, el 1 y el 5 de julio de 1925. En la nota interna a la que se hace referencia se especifican las condiciones del transporte y se adjuntan las facturas de algunos de los materiales.

48 BCOECP, 4, Lima, 17 de mayo de 1923, págs. 9-11.

49 Ibídem, 5, Lima, 12 de octubre de 1923, págs.7-9.

50 Centurión Herrera, Enrique: El Perú actual y las colonias extranjeras. La realidad actual y el extranjero en el Perú a través de los años 1821-1921, Instituto Italiano, Bérgamo, 1924, págs. 371-372. 
En los años siguientes la Compañía, al margen de su actividad comercial y de transporte de pasajeros, estaría presente en algunos momentos relevantes de las relaciones entre el Perú y España. En noviembre de 1923 el "Manuel Arnús" llevaría de regreso a España al cardenal Benlloch, en viaje oficial al Perú en representación del Papa y de Alfonso XIII. ${ }^{51}$ La visita se inscribía en el marco de la nueva dinámica de aproximación diseñada por Leguía y Primo de Rivera, que encontró un nuevo escenario para manifestarse con motivo de la conmemoración en 1924 del Centenario de Ayacucho. En la agenda el gobierno del Perú programó una serie de exposiciones de productos hispanoamericanos, cuya organización correría a cargo de los países participantes. La Feria-Exposición de Productos Hispano Peruanos se proyectó para el mes de diciembre. Los preparativos en la Península corrieron a cargo de la Junta Nacional del Comercio Español en Ultramar y en Lima de la Cámara Española de Comercio. La Corona prestaba su apoyo con una subvención para gastos de propaganda, y la Trasatlántica, “...dando una vez más pruebas del interés que pone siempre en facilitar la intensificación de las relaciones comerciales entre España y los países de Ultramar", concedió fletes gratuitos en el "Manuel Arnús", que saldría desde Barcelona con los productos procedentes de los distintos puertos del Mediterráneo, y en el "San Carlos" que conduciría a Cádiz a los de las regiones del norte y noroeste para ser embarcados por el "Manuel Arnús". Los muestrarios debían ajustarse a las condiciones y fechas de envío publicadas por la Compañía. ${ }^{52}$

Los comerciantes, empresarios y agentes españoles organizados en la Cámara de Comercio plantearían desde muy pronto sus prevenciones y demandas. De manera recurrente se pidió a la Compañía que adaptara las tarifas a las de las demás compañías, porque si eran demasiado elevadas no podrían con la competencia. De hecho desde mediados de agosto de 1923 la Pacific Steam Navigation y la Grace Line habían tomado medidas abaratando sus tarifas en un $30 \% .{ }^{53} \mathrm{La}$ otra reclamación fue que se redujera el tiempo del trayecto mejorando la velocidad de los buques y eliminando algunos de los puntos del recorrido. Eso sí, interesaba sobremanera incluir

51 Mercurio. Revista Comercial Iberoamericana, XXIV, 454, Barcelona, 10 de enero de 1924. El cardenal había llegado al Callao en el vapor norteamericano "Santa Lucía", procedente de Valparaíso.

52 "La Feria-Exposición de Productos hispanoperuanos en Lima". Ibídem., XXIV, 469, Barcelona, 7 de agosto de 1924.

53 "Nota institucional de la Cámara Española de Comercio al Directorio de la Trasatlántica Española”. BCOECP, 5, Lima, 12 de octubre de 1923, págs. 8-9. 
en el itinerario el puerto de Nueva York, que aseguraría un mayor número de pasajeros y permitiría colocar productos españoles. ${ }^{54}$ En cualquier caso había un argumento incontestable, la Trasatlántica debía tener presente que era una compañía subvencionada y por tanto había de actuar en beneficio de los intereses generales de la nación.

En definitiva, los negocios eran los negocios, y desde el principio surgieron los inevitables conflictos de intereses. El fiel de la balanza se inclinaría hacia el más fuerte, la Trasatlántica, que podía intervenir en el precio de los fletes y en la clasificación de las mercancías que transportaba desde los puertos del Callao y Mollendo. Cuando en 1925 el presidente de la Cámara Aurelio Díaz Ufano se dirigió al ministro de Trabajo, Comercio e Industria, elevando las quejas de los comerciantes y solicitando que se abriera el monopolio que ejercía la Compañía desde el único puerto de Barcelona para el transporte de paquetes postales, sólo consiguió una bonificación del $30 \%$ en los pasajes de comerciantes y agentes españoles con residencia fija en la República, además de a los socios de la Cámara. ${ }^{55}$

Las cosas no irían mejor para la Compañía, que arrastraba un fuerte déficit, a pesar de las inyecciones económicas del gobierno. Por Real Orden de 9 de junio de 1926 se reducía de 12 a 11 el número de expediciones anuales y el servicio quedaba estancado sin que aumentara el número de buques ni disminuyera la duración del trayecto. Las alarmas se dispararon y en 1927 la Cámara Española de Comercio decidió intervenir encargando un informe a un experto, Emilio Huidobro, para ser remitido a la Gerencia de la Trasatlántica y a las Cámaras españolas en Guayaquil y Valparaíso. "El servicio de la Trasatlántica Española al Pacífico" ponía en evidencia el incumplimiento del contrato vigente (firmado en 1925), que establecía un aumento de contingentes con tres nuevos barcos del tipo del "Arnús". La línea era rentable en los puertos del Pacífico, y entraba en pérdidas al llegar al Atlántico en el recorrido por Colombia, Venezuela y las Antillas. Para revertir la situación sería preciso remodelar el itinerario incluyendo nuevos puertos en España (Vigo y la Coruña, copados por la competencia) y eliminando los caribeños. La nueva ruta debería tener como puntos de referencia Nueva York y Panamá. Afortunadamente el gobierno

54 Memoria presentada por la Junta Directiva de la Cámara Española de Comercio del Perú a la Junta General el 20 de julio de 1924 siendo presidente el Sr. Aurelio Díaz Ufano, Imprenta y Litografía T. Scheuch, Lima, 1924, págs. 5 y 12.

55 BCOECP, 7-8, Lima, 17 de mayo de 1925, págs. 28-29. 
estaba adoptando una política "patriótica" y para mantener su presencia en esas aguas incrementaba las subvenciones a la Compañía. ${ }^{56}$

\section{La supresión y sus secuelas}

Por poco tiempo. El 27 de agosto de 1928 el gobierno ordenaba la supresión de las líneas de extensión al Pacífico, “....con el consiguiente perjuicio para la Compañía Trasatlántica, que a costa de grandes sacrificios la había establecido, con el patriótico deseo de siempre, de fomentar las relaciones espirituales y comerciales entre España y todos los países americanos de habla española..”. La Compañía protestó la decisión, ya que suponía la disminución de las subvenciones — que se concedían por "milla recorrida"-, el dique seco para algunas unidades y graves perjuicios para los trabajadores..$^{57}$

A pesar de las divergencias y de las críticas, para los comerciantes y empresarios españoles en el Perú era una verdadera catástrofe. La reacción de la Cámara se materializó en un oficio que Ventura Martínez de la Torre, en nombre de la Directiva, dirigió personalmente al general Primo de Rivera el 15 de septiembre de 1928. La solución no estaba en la desaparición de la Trasatlántica, sino en su reforma. Se trataba de reducir los costes y aumentar la competitividad, ya que en el momento los buques tardaban en llegar a Cádiz entre 35 y 40 días mientras compañías extranjeras iban del Callao a la Coruña en 20. La Cámara reiteraba la pertinencia de suprimir algunos puertos del itinerario para recortar el tiempo de travesía, o implantar una nueva ruta, la de Cádiz, Vigo, Nueva York, La Habana, Panamá y Sudamérica. Apelaba a la veta patriótica a la que la Compañía era tan sensible: había que defender la presencia de España en el Pacífico, sobre todo ante el amenazador avance de los Estados Unidos. Las cercanas celebraciones de las Exposiciones de Sevilla y Barcelona en 1929 eran

56 Ibídem., 18, 19, 20, Lima, octubre de 1927, págs. 31-33. Huidobro era profesor de las dos Universidades de Lima, San Marcos y la Católica, y redactor principal del BCOECP. En 1925 había estado en España para conocer su realidad económica y hacer campaña propagandista en la prensa española.

57 Alegaciones de la Compañía Trasatlántica en la liquidación que ordena la Ley de 23 de julio de 1932, Gráficas Reunidas, Madrid, 1933. Con motivo de la supresión por el gobierno republicano (presidido por Manuel Azaña) de la vigencia del contrato que se había firmado el 21 de agosto de 1925, el representante de la Compañía José Gil de Biedma presentaba al Ministerio de Marina los argumentos documentados en los que mostraba el cumplimiento de todos los compromisos y los daños materiales y personales que la decisión conllevaba. 
otros motivos de peso para seguir en la brecha. ${ }^{58}$ Durante un tiempo los comerciantes y empresarios españoles, a través de la Cámara, hicieron gestiones para que el gobierno reanudara la línea de vapores. Aprovecharon la visita oficial del vizconde de Casa Aguilar en misión especial para recabar apoyos para la creación de una Ciudad Universitaria en Madrid, y la estancia del buque escuela Juan Sebastián Elcano a cuyo comandante Lago de Landos pidieron mediación, y finalmente enviaron una nota al Ministerio de Estado el 1 de diciembre de 1929 en que acudían a lo más inmediato, la preparación de la Exposición Iberoamericana de Sevilla. ${ }^{59}$

Las cartas estaban echadas. En el itinerario que la Compañía presentaba para 1929 ya no figuraban los puertos del Pacífico. En el BCOECP editado en mayo, la etiqueta de "agentes de la Trasatlántica" había desaparecido del anuncio que mantenían los hermanos Gallo. En el número que cerraba el año se reproducía la Rescisión del Contrato de Servicios Transoceánicos entre el Estado y la Compañía Trasatlántica. ${ }^{60}$ Por su parte, en un escueto comunicado del ministro de Relaciones Exteriores Pedro José Rada y Gamio, el gobierno peruano se daba por enterado “...La Compañía Trasatlántica Española que hacía servicio a Sudamérica ha modificado su itinerario. Sus vapores solo llegan hoy hasta Colón". ${ }^{61}$

El balance más completo y equilibrado de lo que fue y lo que hubiera podido ser la Trasatlántica se debe a Antonio Pinilla Rambaud, cónsul de España en Lima desde 1918 y excepcional conocedor de los temas que por su cargo tenía asignados (comercio, inmigración, situación de los españoles y cultura). Su larga permanencia en el puesto y la diligencia y profesionalidad con las que actuó le convierten en un actor fundamental del proceso. Su gestión quedó registrada en una secuencia de informes y propuestas, varios de ellos editados, que son piezas básicas para la reconstrucción de muchos aspectos de las relaciones entre el Perú y

58 BCOECP, 24-25, Lima, septiembre-octubre de 1928, págs. 16-17. El documento es presentado también ante la colonia española afectada por la supresión. El presidente de la Cámara carga las tintas en la despreocupación de la Compañía, que ha hecho caso omiso de las observaciones que hubieran podido redefinir las relaciones con los comerciantes del Pacífico. Memoria Presentada por el Presidente de la Cámara Española de Comercio del Perú. Don. Ventura Martínez de la Torre a la Asamblea General el 7 de julio de 1929, Imprenta Scheuch, Lima, 1919, págs. 9-10.

59 Memoria presentada a la Junta Directiva de la Cámara Oficial de Comercio del Perú a la Asamblea General el 7 de julio de 1930, Imprenta La Opinión Nacional, Lima, 1930, págs. 9-10.

60 BCOECP, 35, Lima, diciembre 1929, págs. 13-14. Para entonces, el Directorio Militar había encargado informes a varias comisiones cuyos dictámenes coincidieron en la conveniencia de suprimir el servicio.

61 Memoria que presenta al Congreso Ordinario de 1929 el Dr. Pedro Rada y Gamio, Imprenta Torres Aguirre, Lima, 1929, pág. DXXXIV. 
España. Fue un hombre práctico, que potenció los canales de afirmación de la colonia española en el Perú e impulsó los intercambios a todos los niveles. Su incorporación coincidió con el fin de la primera guerra mundial, y ya apostó entonces porque la Trasatlántica estableciera sus servicios en el Perú para así capitalizar las posiciones que el comercio español había ganado, que alcanzaban la nada despreciable suma de medio millón de libras, “...en tal caso la conveniencia de una línea de vapores propia, nos era necesaria...". Sin embargo la realidad se encargaría de hacerle cambiar de opinión.

Cuando los países europeos y los Estados Unidos estuvieron en paz, “...emprendieron una feroz ofensiva económica de competencias por el mercado peruano y el intercambio comenzó a descender hasta un promedio de 180.000 libras para los tres últimos años..." (se refiere al trienio 19261929). La Pacific Steam Navigation, que hacía dos servicios mensuales desde los puertos del norte de España y el Callao, y la Compañía di Navegazione Generale Italiana, que hacía un servicio mensual con Barcelona, tenían todas las ventajas frente a la Trasatlántica que ofrecía un servicio no competitivo. En cuanto al traslado de mercancías españolas, “... en los siete años que ha funcionado la línea tengo la seguridad de que no ha transportado más de cien toneladas de carga comercial" y todavía más insignificantes eran las importaciones peruanas. ${ }^{62}$ La organización del servicio de pasajeros no estuvo mejor programada,

“...En los meses de la primavera europea siempre faltaban plazas para los buques buenos, pues la Compañía sólo tenía asignado al Perú un pequeño número de ellos (...). Nada quiero decir del absurdo económico que resultaba iniciar un viaje de retorno de Valparaíso con los enormes gastos del paso por el Canal de Panamá para solo llevar 19 pasajeros de primera clase en viaje directo a España, pues había que reservar sus cuotas respectivas a los otros países por los que hacía escala el barco, como Colombia, Venezuela, Puerto Rico, que eran los que daban más contingente de carga y pasajeros".

62 Los consulados son los que proporcionan datos sobre el intercambio comercial entre España y el Perú que a su vez proceden de la información gubernamental del servicio de aduanas. Las referencias no son completas ni continuas y no es posible elaborar series completas, aunque con diferencia Barcelona es el primer puerto de salida y arribo. En cualquier caso, si hay que hacer una excepción, sería de nuevo el cónsul Pinilla autor de varios informes sobre el comercio hispanoperuano, entre ellos El comercio hispanoperuano: su realidad y sus posibilidades, Cámara Oficial Española de Comercio del Perú, Lima 1924 (editado en Madrid por el Ministerio de Estado en 1925). En el BCOECP, 39, Lima, abril 1930, págs. 27-30, hacía un balance desolador en el que constataba que en 1928 las importaciones de productos españoles suponían el 0,9\% del total del Perú, mientras las exportaciones a España prácticamente habían desaparecido. 
A ello había que sumar la vejez y lentitud de los buques asignados a la línea del Pacífico, con excepción del "Manuel Arnús", y los trasnochados reglamentos que hacían la vida a bordo "terriblemente aburrida". De todo ello pudo dar fe en un viaje de 45 días que le trasladó de Barcelona al Callao en octubre de 1925.

Estos argumentos estaban en el Informe que elaboró en 1930 y que publicó el BCOECP. Concluía que la supresión del servicio de la Trasatlántica había sido inevitable y lógica. Perfilando las propuestas de Huidobro y de la Directiva de la Cámara, estimaba que para que una línea española fuera rentable tendría que pasar por Nueva York y lo argumentaba: el comercio del Perú con los EEUU suponía el 43\% de las importaciones peruanas y el 39\% de sus exportaciones, y habría que tratar de capitalizarlo mediante una línea que partiera de Valparaíso y en el viaje de retorno recogiera la carga que en Chile, Perú y Ecuador hubiera para España, y además tomara una parte del enorme volumen de algodón, azúcar, minerales y lanas, que el Perú exportaba a los Estados Unidos. En cuanto a los pasajeros

“... Una línea española con buques nuevos, de un andar mínimo de quince millas a la hora, con régimen moderno interno donde la vida a bordo sea entretenida y no monacal con apago general de luces y cerrazón de salones a las once de la noche, estimo que sería todo un éxito pues transportaría parte de la carga enorme que siempre hay en espera de embarque con destino a Nueva York y luego llevaría el pasaje que desde el Perú va a los Estados Unidos y parte del que va a Europa".

La Compañía española debería ofertar sólo pasajes de segunda clase que eran los que más se solicitaban, y además consumo de alcohol, que no proporcionaba la Grace Line debido a la prohibición y que sería un tirón para los clientes. ${ }^{63}$

Había que ser realistas. A lo largo de 1931 los comerciantes españoles gestionaron bonificaciones con empresas navieras extranjeras (a las inglesas e italianas se sumó la W.R.Grace and Cía). Poco había que defender porque el declive se hizo aún más profundo a raíz de la crisis de 1929 y de la inestabilidad política, con todo lo que llevaba aparejado, por la que pasaron ambos países. ${ }^{64}$

63 BCOECP, 39, Lima, abril de 1930, págs. 27-30.

64 En el Perú en agosto de 1930 el coronel Sánchez Cerro derrocaba al régimen de Leguía, en España en enero el Rey reemplazaba a Primo de Rivera por el general Berenguer, en un intento desesperado de perpetuar a la Monarquía. 
Para entonces Colón, en el istmo de Panamá, volvía a ser el límite de la Trasatlántica, que se deslizaba ya por una pendiente que conduciría a la ley de 23 de julio de 1932 que puso fin a los contratos con el gobierno. El primer representante diplomático español en Lima designado por la II República, Antonio Jaén y Morente, ofrecía un testimonio desolador de la ausencia total de buques españoles en el Callao y se preguntaba si "no van barcos porque no hay comercio, o no hay comercio porque no van barcos". El buque de la Grace Line que le llevó hasta Panamá en su viaje hacia el Perú “...puso, como es de cortesía, la bandera española, por ir a bordo un ministro de España. Pero izando la bandera de la época monárquica, porque no conocían ni tenían otra. Fue rápidamente sustituida porque dos damas americanas, una peruana y otra chilena, confeccionaron la primera bandera de la República que pasó el Pacífico en barco norteamericano en febrero de 1933". ${ }^{65}$

En los años siguientes los gobiernos de la II República barajarían proyectos para la remodelación de las comunicaciones interoceánicas. Uno de ellos, impulsado por el ministro Giral, preveía el establecimiento de dos líneas al Pacífico: una de ellas partiría de Barcelona y arribaría directamente a Puerto Rico, para de ahí poner rumbo al Pacífico, regresando vía América Central, Cuba y Nueva York; la otra, también desde Barcelona, a Nueva York, América Central y costas del Pacífico para retornar por Venezuela y Puerto Rico. Estarían atendidas por los vapores "Colón", "Habana", "Magallanes", "Marqués de Comillas" y "Manuel Arnús". ${ }^{66}$ No pasaría del foro parlamentario, como tampoco lo haría el Proyecto de Ley de Comunicaciones Marítimas aprobado por el Consejo de Ministros el 23 de marzo de 1934 y que programaba el funcionamiento de hasta cinco Compañías Marítimas. Ninguna tenía como destino el Pacífico. En realidad ninguna llevaría a ninguna parte en los tiempos sombríos que se perfilaban en el horizonte español.

65 Jaén Morente, Antonio: La lección de América, Sucesores de Rivadeneyra, Madrid, 1933, pág. 117.

66 Mercurio. Órgano Oficial de la Cámara Española de Comercio del Perú, 52, Lima, junio de 1933, pág. 7. 